\title{
Stability Analysis of Tailings Dam under Muddy Water Infiltration
}

\author{
Zhi-fei SONG ${ }^{1 \mathrm{a}}$, Fa-liang ZHAO ${ }^{2 \mathrm{~b}}$, Qin-huan $\mathrm{CUI}^{3}$,Jian-qiang $\mathrm{WANG}^{4}$ \\ ,2,3,No.5 Jin Yuan Zhuang Road, Shi Jing Shan District, Beijing, China \\ asong59672@163.com, ${ }^{\mathrm{b}}$ zhaofl01@163.com
}

Keywords: Seepage, Stability, Analysis

Abstract. Tailings dam is an important control project of mine safety, once the instability, the greater harm. Tailings dam seepage damage is the main reason about tailings dam safety accident and tailings dam seepage problem belongs to the muddy water seepage. By considering the main hydraulic factors of the seepage problem, use finite element software to analyze its seepage stability. Test the safety of dam running state and get the influence law of permeability coefficient and aquitard on dam safety.

\section{Introduction}

The tailings are discharged in a slurry form, stored in the tailings dam ${ }^{[1]}$. Tailings dam is a special industrial buildings and is an important control project of mine safety. Data suggest that more than $90 \%$ accidents are related to water about tailings dam which mainly is the destruction of seepage. Seepage damage is one of the main causes of the tailings dam accidents. Due to higher dam saturation line, it is easily to cause slope seepage, and piping, resulting in water-saturated tailings dam slope, soft, until the dam landslide.

Tailing dam is consists of initial dam and tailings stacking dam. The initial dam is one structure which support stockpiling tailings dam. Tailings stacking dam is sedimentary body in the process of slurry discharge it essentially equivalent to the sand soil slope after the hydraulic separation. The filling process of tailings dam is very long, the construction process and the production run simultaneously. If instability, great harm, ensures tailings dam safety is a key in production design. Within the suspended solids continuously deposited, penetration path and overall permeability coefficient are constantly changing ${ }^{[2]}$; so tailings dam seepage problem belongs muddy water seepage problem. Under the influence of various mechanisms, porous medium porosity is changing; permeability coefficient and permeability paths are in a non-steady state. In this paper, taking a tailings dam in northern China as an example, consider percolation head (pore water pressure), osmotic gradient (flow rate or penetration), water seepage discharge and other factors to study he seepage stability of the tailings dam.

\section{Engineering situation}

The initial dam of a tailings dam in northern China is a permeable rock fill dam, dam crest elevation is about $228 \mathrm{~m}$, wide $4 \mathrm{~m}$, height $16 \mathrm{~m}$, length $74.4 \mathrm{~m}$. After more than 10 years of running the initial dam, the outline dimensions still meet the design requirements: dam surface smooth, the initial dam has no obvious subsidence, landslide, cracks, mass flow and piping phenomenon. At present, the elevation of tailings dam is $282.7 \mathrm{~m}$, and the height of the beach is $280.1 \mathrm{~m}$, the height of the main water level is $269.3 \mathrm{~m}$.

\section{Seepage gradient}

Through numerical analysis software to simulate muddy water seepage, we can obtain Seepage velocity vector cloud and total head contour contours in main dam normal condition. 


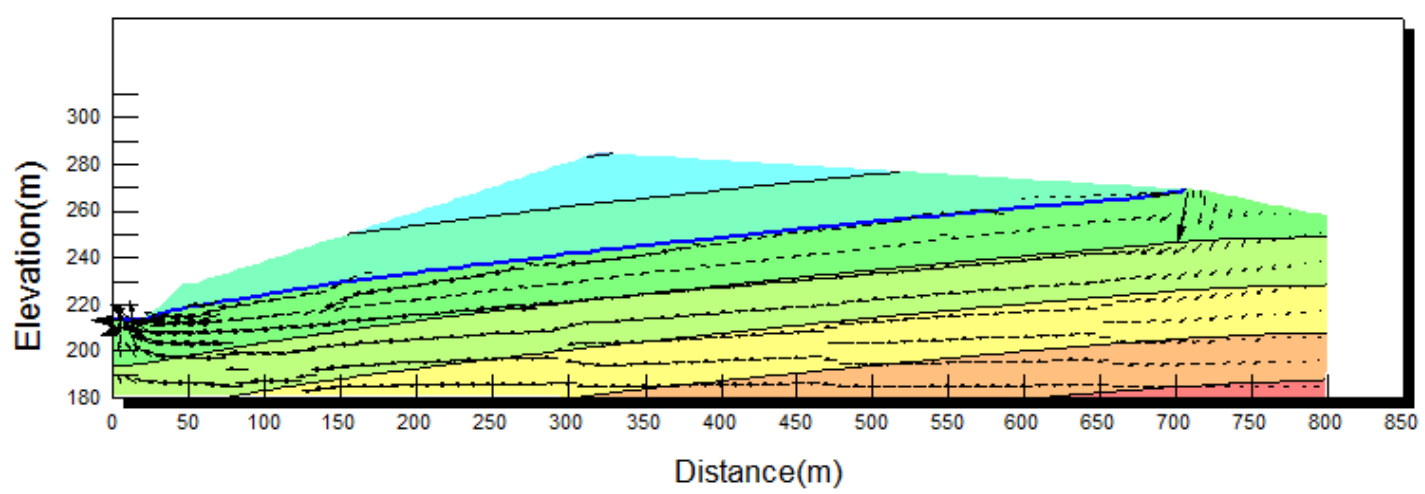

Fig. 1 Seepage velocity vector cloud

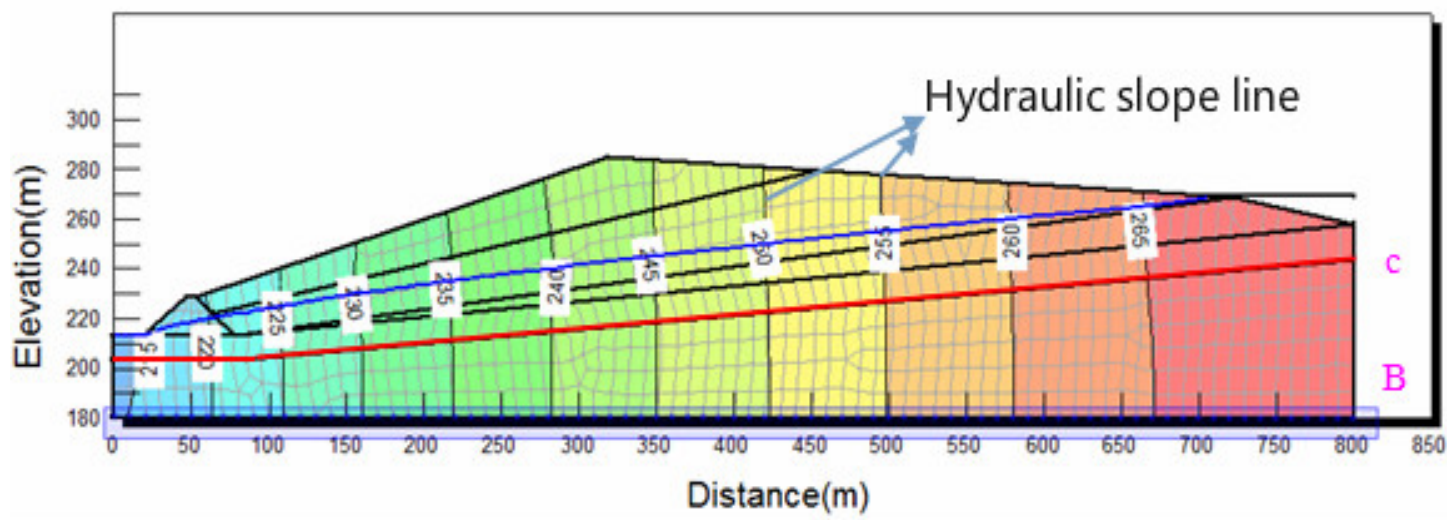

Fig. 2 total head contour contours

Through the seepage calculation, we can obtain the seepage velocity vector cloud, in figure.1: from top to bottom for osmotic pressure contour, blue 0 pressure line as the infiltration line. we can also obtain the total head contour contours, then get the flow velocity, black pointed that seepage velocity vector, the following parts of the infiltration line are vector images. Based on solving data has seepage gradient inspection for the following parts: Seepage gradient will make piping failure in overflow port, The seepage in the dam foundation lead to instability of the dam foundation and piping failure. To test the stability of the dam body requirements, we should also check anti-permeability strength in other place.

Table 1 Hydraulic grade, allowing slope calculation table

\begin{tabular}{ccccc}
\hline Position & Damage form & $\begin{array}{c}\text { Hydraulic gradient } \\
i\end{array}$ & $\begin{array}{c}\text { Allowable } \\
\text { gradient }\end{array}$ & Remarks \\
\hline $\begin{array}{c}\text { Overflow } \\
\text { point } \\
\text { foundatio } \\
\mathrm{n}\end{array}$ & piping & 0.202 & $0.45 \sim 0.60$ & $\begin{array}{c}\text { Engineering } \\
\text { allowed }\end{array}$ \\
Interface & piping & 0.1125 & $0.52 \sim 0.68$ & $\begin{array}{c}\text { gradient: } \\
\text { erosion }\end{array}$ \\
\hline
\end{tabular}

According to table 1, this seepage stability of several key parts meets the basic requirements.

\section{Seepage flow}

Through simulation, we could get the drift net and the flow of tailings dam under the action of muddy water infiltration in normal condition, which is important hydraulic parameters of seepage analysis.

The normal way of the tailings dam backwater is setting water drainage tunnel and underground water pipe to the bottom of the pump station for the mine return. With single outlet discharge of round window type and non-pressure flow or half pressure flow in the drainage hole, brief calculation according to the single hole is as follows:

$$
Q=\mu A \sqrt{2 g h}
$$


Type: $\mathrm{Q}$ represent the discharge, $\mu$ represent discharge coefficient, which is set 0.95 ; A represent the area of orifice; $\mathrm{G}$ represent the acceleration of gravity; $\mathrm{H}$ represent spillway tunnel and effective head. We can calculate the minimum discharge flow with the normal operating condition of the reservoir water level, which is about $1.16 \mathrm{~m} 3 / \mathrm{s}$. The seepage flow of the dam body and the dam foundation is $0.0046696 \mathrm{~m} 3 / \mathrm{s}$ and $0.00034389 \mathrm{~m} 3 / \mathrm{s}$, which is far less than the design flow, and which will not affect the stability of the dam and dam foundation.

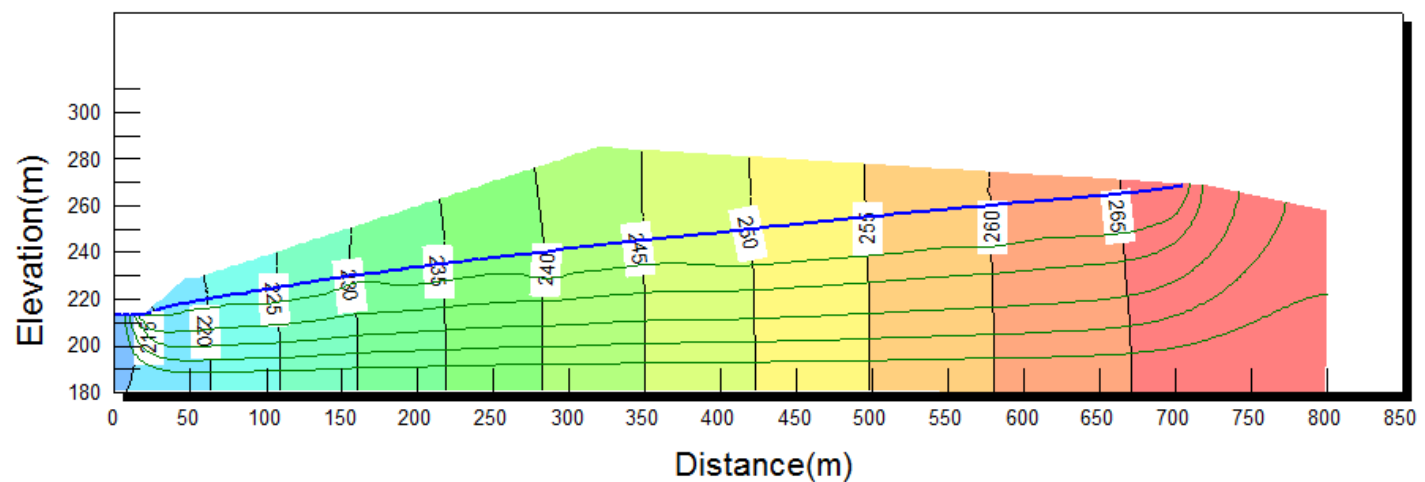

Fig. 3 the drift net

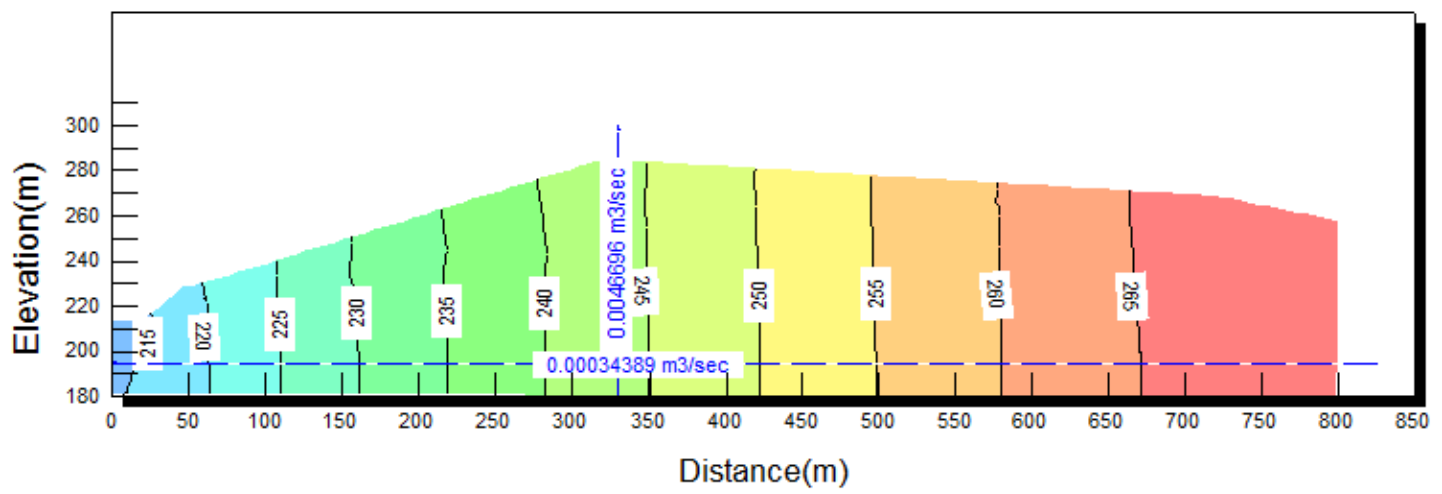

Fig. 4 the flow

\section{Permeability of tailings dam}

Tailings dam complex engineering characteristics lies in the sedimentation law of its own, the generality of slurry after emissions, namely is the limitation of tailing water carrying sand ability, the coarse particle first deposit, finer particles deposited sequentially, making the material of dam body from top to bottom gradually is: gravel sand, coarse sand, medium sand, fine sand, silt, silt soil, sometimes tailings mud soil. Because of this, tailings dam in horizontal and vertical reflects the difference of permeability anisotropy.

The distribution of the tailings sand is also related to the concentration of the slurry and the composition of the tailings. The distribution of tailings ore in the beach, the periodic immersion of precipitation pool and fine particle precipitation thin-layer in suspension will cause sharp stratification of the thin layer of tailings mud and make the tailings mineral sand layer long with the narrow and thin tailings mud. Due to its poor permeability, it is likely to cause adverse effects on the dam body.

Influence of anisotropy on the Seepage Stability. In the analysis software, take $K_{y}=$ Ratio $\times K_{x}$. By adjusting the size of Ratio, to consider the impact of sand layer anisotropy on safety and stability. To analysis seepage stability when $K_{i, y} / K_{i, x}=1.0,0.5,0.2,0.1 \quad(i=1,2,3,4,5)$ are respectively discussed in the same layer. 


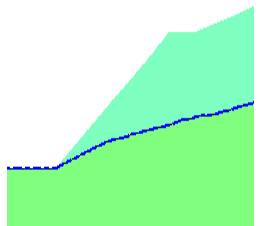

Ratio=1

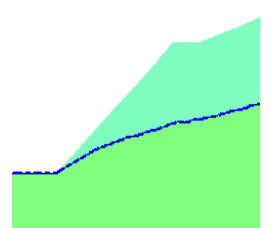

Ratio $=0.5$

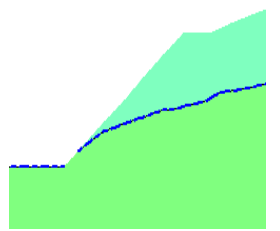

Ratio $=0.2$

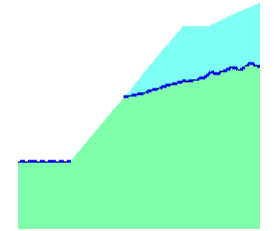

Ratio $=0.1$

Fig. 5 overflow point with the Ratio value change map

From the fig. 5 , the position of the Ratio $=0.5$ is slightly higher than the saturation line at $\mathrm{Ratio}=1$; the overflow point upward shift when Ratio $=0.2$, saturation line overflow point was obviously move to the midpoint of the initial dam face. The same position with the Ratio becomes smaller, pore water pressure becomes larger.

Influence of seepage stability consider low-permeability layer. In the medium layer of the dam exist low-permeability layer formed by silt soil, remove this layer and then analyze the influence of seepage stability of the tailings dam.

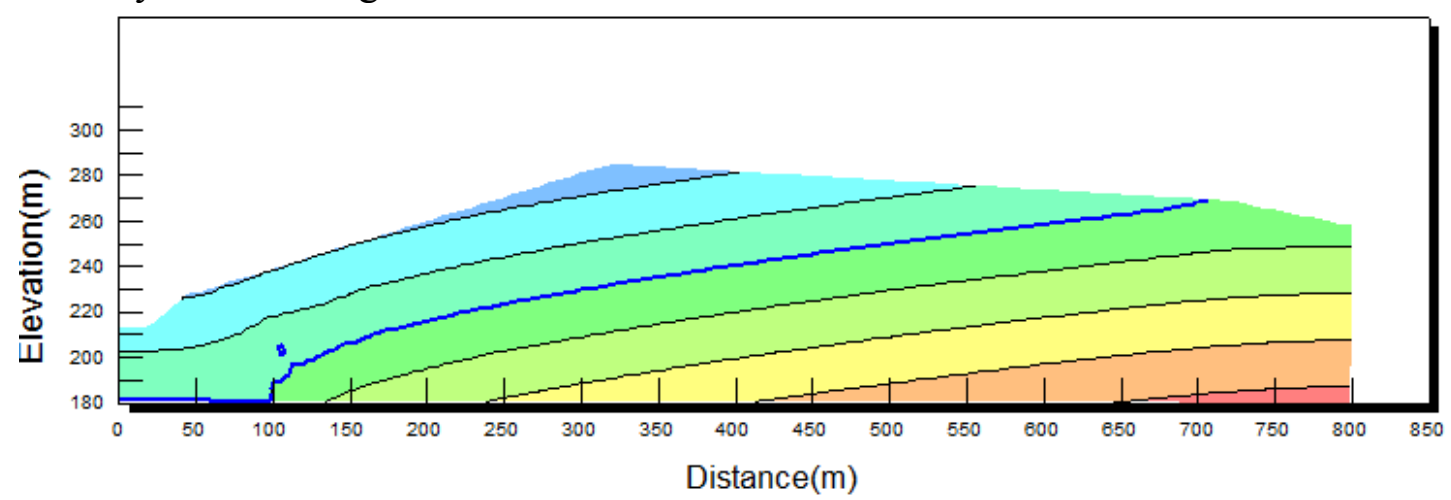

Fig. 6 infiltration line form

Table 2 The relationship between safety coefficient with Ratio

\begin{tabular}{ccccc}
\hline Ratio & Ordinary & Bishop & Janbu & GLE \\
\hline Ratio=1 & 1.576 & 1.647 & 1.581 & 1.645 \\
Ratio=0.5 & 1.537 & 1.611 & 1.543 & 1.609 \\
Ratio $=0.2$ & 1.451 & 1.526 & 1.460 & 1.525 \\
Ratio=0.1 & 1.385 & 1.450 & 1.397 & 1.448 \\
$\begin{array}{c}\text { low-permeability layer } \\
\text { (removed) }\end{array}$ & 1.644 & 1.662 & 1.644 & 1.660 \\
\hline
\end{tabular}

The permeability of the tailings dam and the anisotropy of the weak permeable layer are affected by the stability of the tailings dam. Figure 4.6- Figure 11 for the removal of the weak permeable dam water infiltration line shape. The position of the overflow point to the dam foundation is reduced, and the saturation line is obviously lower than before. Table 2 records when the Ratio is constantly decreasing and removing the weak water layer the safety evaluation coefficient was calculated by Ordinary, Bishop, Janbu and GLE. By comparison, The smaller the Ratio value, the corresponding decrease of the Fs value.

\section{Summary}

1) The safety of the tailings dam under the condition of the status quo of the tailings dam, which meets the requirements of the seepage stability. 
2) The greater the permeability coefficient, the smaller the Ratio value, the higher the infiltration line. The greater the saturation zone of the tailings dam, the decrease of the shear strength of the tailings sand, adverse effects on the stability of the tailings dam.

3) After removing the weak water permeable layer, it is beneficial to the stability of the dam.

4) The seepage characteristics of the dam will greatly affect the position of the infiltration line, Drainage facilities, drainage and drainage, drainage facilities, appropriate position in tailings dam, It can effectively reduce the height of the line, to ensure the safety of the.

\section{Acknowledgements}

This work was financially supported by the national natural science foundation of China (41202214), science and technology Beijing nova plan (Z121106002512008).

\section{References}

[1] YU Guo,YANG Zuo-ya etc. Dynamic Properties of Yangla Copper Tailings Material [J].Journal of Chongqing Jianzhu University, Vol6. 107- 110 (2008).

[2] DANG Fa-ning,LIU Yun-he etc. The muddy water seepage theory and its engineering application[J]. Science in China(Series E:Information Sciences), Vo19. 1029- 1036(2006).

[3] WANG Zheng-yuan.Study on the treatment of reservoir dam foundation[J] .Modern Business Trade Industry, Vol17(2012). 